\title{
POLYESTER RESIN HAZARDS
}

\author{
BY \\ L. B. BOURNE and F. J. M. MILNER
}

From the Cossor Group of Companies

(RECEIVED FOR PUBLICATION AUGUST 15, 1962)

\begin{abstract}
Polyester resins are being increasingly used in industry. These resins require the addition of catalysts and accelerators. The handling of polyester resin system materials may give rise to skin irritations, allergic reactions, and burns. The burns are probably due to styrene and organic peroxides. Atmospheric pollution from styrene and explosion and fire risks from organic peroxides must be prevented. Where dimethylaniline is used scrupulous cleanliness and no-touch technique must be enforced. Handling precautions are suggested.
\end{abstract}

For some 20 years polyester resins have been available and during this time they have been used in increasing quantities; the annual output in this country is now of the order of 9,000 tons. Polyesters are unsaturated thermo-setting resins which can be moulded in almost any shape and size. Alone they are usually not strong enough for commercial purposes but when combined with a reinforcing material, such as glass fibre, or fillers, such as glass dust or sand, they offer considerable possibilities.

Vorländer (1894) was apparently the first to

TABLE 1

PRODUCTION OF POLYESTER RESINS

\begin{tabular}{r|r}
\hline Year & Tons \\
\hline 1954 & 300 \\
1955 & 900 \\
1956 & 2,200 \\
1957 & 3,100 \\
1958 & 4,800 \\
1959 & 6,700 \\
1960 & 9,000 \\
\hline
\end{tabular}

investigate glycol maleates, further work being carried out by Kienle and Hovey (1930) and in Britain patents relating to polyester resins were taken out in 1932 (British Patent 393034). Further development in the United States proved that these had excellent properties for radar work. It was eventually found that they had valuable laminating properties particularly when used with glass fibre.

The growth in popularity of the resin is shown by the Board of Trade figures of production since 1954 (Table 1).

It is estimated that the consumption of reinforced plastics will double in the next five years (Resin News, 1961).

Parkyn and Hulbert (1959) analysed the industrial use of polyester resins (Table 2).

Polyester resin is usually supplied as a mixture of polyester and styrene. Setting and curing take place by cross-linking of the polyester chains by styrene. This reaction is extremely slow but can be hastened using catalysts with or without accelerators. The

TABLE 2

INDUSTRIAL USES OF POLYESTER RESINS (PARKYN AND HULBERT, 1959)

\begin{tabular}{|c|c|c|c|c|c|c|c|}
\hline \multirow{2}{*}{ Application } & \multicolumn{7}{|c|}{ Percentages of Total Resin Distributed per Annum* } \\
\hline & 1951 & 1952 & 1953 & 1954 & 1955 & 1956 & 1957 \\
\hline $\begin{array}{l}\text { Aircraft and related industry } \\
\text { Shipbuilding and related industry } \\
\text { All forms of land transport (cars), lorries, railways, buses, etc. } \\
\text { Corrugates and sheeting } \\
\text { Casting } \\
\text { All other, including rod stock, pipes, etc. }\end{array}$ & $\begin{array}{r}50 \\
5 \\
5 \\
5 \\
20 \\
15\end{array}$ & $\begin{array}{r}45 \\
10 \\
5 \\
15 \\
10 \\
15\end{array}$ & $\begin{array}{r}40 \\
10 \\
5 \\
20 \\
5 \\
20\end{array}$ & $\begin{array}{l}20 \\
10 \\
10 \\
30 \\
10 \\
20\end{array}$ & $\begin{array}{r}20 \\
5 \\
7 \\
40 \\
20 \\
8\end{array}$ & $\begin{array}{l}15 \\
15 \\
15 \\
30 \\
15 \\
10\end{array}$ & $\begin{array}{r}10 \\
18 \\
25 \\
28 \\
10 \\
9\end{array}$ \\
\hline
\end{tabular}

*These figures do not include polyester resin used in paints and lacquers, for plaster or wood impregnation, or for textile coating. Most general moulding has been fitted into one of the first four categories, depending on its ultimate use. 
resin mixes readily with fillers and in addition, for moulding purposes, release agents are usually required. Pigments may be added to colour the resulting products.

\section{Basic Chemistry}

In order to understand the essential chemistry of these resins it is necessary first to mention the basis of polymerization. If two or more elements or compounds react together, the reaction may be a simple combination of fixed proportions of each element, e.g. sodium reacting with chlorine to form sodium chloride. One molecule of each element reacts together and a simple compound is formed. Excess of either element present does not affect the product of the reaction which is always formed containing the same proportions of both elements.

With certain organic compounds, however, a different form of reaction is possible by which products are formed which contain indefinite amounts of the reacting substances. Consideration of the formation of polyesters will clarify this.

An ester is the product of reacting an organic acid and alcohol, e.g. $\mathrm{ROH}+\mathrm{R}_{1} \mathrm{COOH} \rightarrow \mathrm{R}_{1} \mathrm{COOR}+$ $\mathrm{H}_{2} \mathrm{O}$. $\mathrm{ROH}$ is an alcohol where $\mathrm{R}$ can represent any chemical group such as $\mathrm{C}_{2} \mathrm{H}_{5}$ as in $\mathrm{C}_{2} \mathrm{H}_{5} \mathrm{OH}$ (ethyl alcohol). $R_{1} C O O H$ is an acid where $\mathrm{R}_{1}$ represents a group such as $\mathrm{CH}_{3}$ as in $\mathrm{CH}_{3} \mathrm{COOH}$ (acetic acid). $R_{1}$ COOR is then ethyl acetate.

Note.- $\mathrm{OH}$ is the alcohol group. There can be more than one such group in a compound. Compounds with more than one group are described as polyhydric alcohols or glycols.

$\mathrm{COOH}$ is the acid group and compounds with more than one group are described as polybasic.

A simple ester such as ethyl acetate is described as monomeric.

If we now consider the reaction of a polyhydric alcohol and a polybasic acid we get the following situation:

$$
\begin{aligned}
& \mathrm{HOOC}-\mathrm{R}-\mathrm{COOH}+\mathrm{HO}-\mathrm{R}_{\mathbf{1}}-\mathrm{OH} \\
& \text { dibasic acid dihydric alcohol } \\
& \longrightarrow \text { HOOC }-\mathrm{R}-\mathrm{COO}-\mathrm{R}_{\mathbf{1}}-\mathrm{OH}+\mathrm{H}_{\mathbf{2}} \mathrm{O} \\
& \text { If further acid is present we get: } \\
& \mathrm{HOOC}-\mathrm{R}-\mathrm{COO}-\mathrm{R}_{\mathbf{1}}-\mathrm{OH}+\mathrm{HOOC}-\mathrm{R}-\mathrm{COOH} \\
& \longrightarrow \mathrm{HOOC}-\mathrm{R}-\mathrm{COO}-\mathrm{R}_{1}-\mathrm{OOC}-\mathrm{R}-\mathrm{COOH}+\mathrm{H}_{2} \mathrm{O} \text {, } \\
& \text { and if further alcohol is present we get: } \\
& \mathrm{HO}-\mathrm{R}_{\mathbf{1}}-\mathrm{OH}+\mathrm{HOOC}-\mathrm{R}-\mathrm{COO}-\mathrm{R}_{\mathbf{1}}-\mathrm{OOC}- \\
& \mathrm{R}-\mathrm{COOH} \\
& \rightarrow \mathrm{HO}-\mathrm{R}_{1}-\mathrm{OOC}-\mathrm{R}-\mathrm{COO}-\mathrm{R}_{1}-\mathrm{OOC}-\mathrm{R}- \\
& \mathrm{COOH}+\mathrm{H}_{2} \mathrm{O}
\end{aligned}
$$

It is evident from this that so long as acid and alcohol are present this reaction can continue, the 3 molecular size of the product growing indefinitely. Such a reaction is called polymerization and the product a polymer. In this case we have a polymer ester or polyester. In practice considerations beyond the scope of this paper limit the size of molecule achieved and a product is obtained that consists of a mixture of molecules of varying size. The case outlined is sufficient to illustrate the formation and formula of a polyester. By variation of the acid and alcohol employed and the reaction conditions, a wide range of polyesters can be achieved that vary from free-flowing sticky liquids to viscous syrups and even solids. The well-known synthetic fibre "terylene" is an example of a solid polyester.

Polyesters are identified with a class of resins known as alkyds and are broadly classified with other resins under the title of "synthetic resins".

A further consideration is now necessary. In the formation of a polyester above, water is formed in the reaction as a by-product. Such a reaction which produces a by-product is termed a "condensation" polymerization. Other polymerization is possible where the reacting substance or substances simply join together to form a new product. This is known as addition polymerization and a very good example of this is the reaction of ethylene to give polyethylene when subjected to very high pressure:

$$
\begin{aligned}
& \mathrm{CH}_{2}=\mathrm{CH}_{2}-\left(\ldots \mathrm{CH}_{2}-\mathrm{CH}_{2}-\mathrm{CH}_{2} \ldots\right) \mathrm{n} \\
& \text { ethylene polyethylene (polythene) }
\end{aligned}
$$

Likewise two molecules of one substance can be linked together repetitively by one molecule of another substance to give a polymeric product. This type of reaction is the one we are interested in since, by selection of $R$ and $R_{1}$ in the instance given, polyesters can be achieved in which the chains can be further linked together by an intermediary such as styrene to produce solid products of excellent electrical and mechanical properties.

This can be represented as follows:

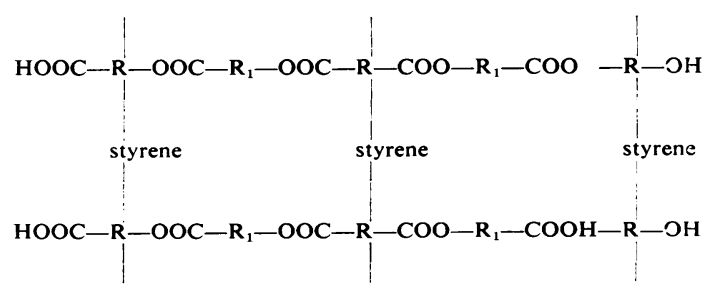

The type of polyester used in this reaction is termed "unsaturated" to denote the fact that there is unsatisfied chemical activity present, capable of being utilized in this manner. 
It is with unsaturated polyesters, their reaction with styrene, the reacting conditions, and the utilization of these processes that we are concerned.

The reaction of polyester with styrene is a very slow process, in fact so slow that the majority of polyesters used in industry are supplied dissolved in styrene and in this condition are still usable after as long as one year. The reaction can, however, be considerably speeded up by the addition of a catalyst and for this purpose certain organic peroxides have been found to be very suitable.

A wide range of peroxides is available for this purpose, all of which have their relative merits of cost, availability, handling, effect on reaction, and effect on reaction product. Commonest in use are benzoyl peroxide, methyl ethyl ketone peroxide, hydroxy-cyclohexyl hydroperoxide, and cumene peroxide, but many others are available.

All are organic peroxides and have similar health hazards. The peroxide may be supplied and used undiluted or as a dispersion in a suitable base such as dibutyl phthalate. The rate of setting and final cure of the polyester depends, among other things, on the concentration of catalyst used (Table 3).

TABLE 3

TIME TAKEN FOR RESIN TO SET AT $25^{\circ} \mathrm{C}$.

\begin{tabular}{c|c}
\hline Catalyst Concentration (\%) & Time of Setting \\
\hline 8 & $45 \mathrm{~min}$. \\
4 & $70 \mathrm{~min}$. \\
2 & $150 \mathrm{~min}$. \\
1 & 8 hours \\
0.5 & 24 hours \\
\hline
\end{tabular}

The temperature of the mix also has an effect on the time of setting (Table 4).

TABLE 4

TIME OF SETTING OF MIX CONTAINING 0.5\% PEROXIDE

\begin{tabular}{c|c}
\hline Temperature & Time of Setting \\
\hline $25^{\circ} \mathrm{C}$. & 2 to 3 days \\
$80^{\circ} \mathrm{C}$. & 15 min. \\
$135^{\circ} \mathrm{C}$. & 3 min. \\
\hline
\end{tabular}

The time of setting is the time for the resin to become hard, but if the physical or electrical properties of the hardened mix are measured it is found that they improve progressively until a value is reached that shows little or no change over a long period. At this stage the resin is described as "cured". Curing can be accelerated by the incorporation of what are called "accelerators". Accelerators not only effect more rapid curing but also increase the rate of setting (Table 5).
TABLE 5

EFFECT OF ACCELERATORS ON TIME OF SETTING

\begin{tabular}{c|c}
\hline Accelerator Concentration (\%) & Time of Setting (min.) \\
\hline Catalyst concentration $2 \%$ at $25^{\circ} \mathrm{C}$. & \\
4.0 & 45 \\
2.0 & 85 \\
0.5 & 150 \\
\hline
\end{tabular}

The accelerator is normally metal soap, most usually cobalt naphthenate, and this is normally supplied as a solution in styrene.

\section{Use of Polyester Resins}

The scope of this article limits the considerations of the use of polyesters to the factors concerning contact with the materials employed. Not all applications need consideration as the techniques involved are essentially similar. Three particular applications typify the general techniques.

1. Finishes.-For finishes, e.g. wood finishes, varnishes, etc. based on polyesters are normally supplied as two component systems. One component contains the resin and accelerator, the other styrene and catalyst. Both components may be diluted with solvent. Two techniques of mixing can be employed:

(a) The two components are measured out and mixed and then placed in a simple spray gun for application.

(b) The components are kept in separate containers and fed through a metering pump to the spray gun so that the correct mixture is achieved by mixing in the gun immediately before spraying.

In both applications there is the possibility of skin contact through handling, although obviously this is greater in $(a)$ than in $(b)$. There is also considerable contact hazard from the sprayed material unless the operation is carried out in a properly designed booth using protective clothing. It should be particularly noted here that such contact with the materials will be with solutions in which the solvent or solvents can also be a hazard in its own right.

2. Fibreglass Mouldings. - This is by far the major use of polyesters. Briefly the process consists of soaking fibreglass, mainly in the form of woven cloths, in mixed resin, squeezing or mangling out the excess resin, and laying the resinated cloth onto a mould to achieve the required shape.

The resin system is normally mixed by hand, but mechanical devices such as stirrers may be employed. Each component is weighed out and added to the basic resin, being thoroughly mixed in before the 
next is added. With care this can be a 'no-touch' operation, but in general practice this operation leads to considerable hand contact, especially where large quantities are mixed.

The fibreglass is normally immersed in the resin system and wrung out by hand or using a wringer or mangle. Gloves can be worn as a protection but all too commonly this operation is carried out without protection. The wet cloth is again applied to the mould by hand and rolled down into position.

Various refinements of this process are possible but generally this is the method used to produce such articles as motor car bodies, van bodies and van roofs, and radar reflectors.

For some applications a spray machine may be used. This machine generally consists of a device by which strands of glass fibre are chopped up and fed to a spray nozzle simultaneously with resin and hardener drawn from separate containers as in a finishing application. The resin-glass mixture is sprayed by the gun onto a mould until the required thickness has been achieved. This system gives less contact hazard except in preparing the machine for use and in cleaning down after use. Contact is still possible in handling the materials on the mould.

In this type of application the system may be either air-set and cured, air-set and cured by heat, or set and cured by heat. Where heat is used it may be applied using heated moulds or the mould and moulding or the moulding alone placed in suitable ovens. In all cases where heat is involved the question of fume hazard must be considered.

3. Casting.-In this application the resin system is normally prepared by hand as in the previous application. Fillers such as powdered slate, finely divided mica, chalk, and glass fibres are normally used, although for some applications, such as embedding biological specimens, only clear unfilled resin is used. The mixture so prepared can vary in viscosity from a fairly free-flowing viscous liquid to a dough, depending on the type and quantity of filler used. The more liquid systems are poured into a mould, sometimes under vacuum. Vacuum may also be applied after pouring, when freedom from porosity is desired, or when the system is being used, for example, to embed a transformer coil, and good impregnation is desired. In the case of dough-like mixtures, particularly those made with glass fibres, the dough may be placed in a two-part moulding tool and moulded under heat or pressure, or usually both.

In all casting applications setting and curing may be carried out by the application of heat.

Ideally the methods employed here lend themselves well to a "no-touch" technique, although this is not very often used. Vapour contact, especially in hot curing, is still a hazard.

Finally, in considering the applications and possible contact of polyesters, regard should be given to solvents, particularly acetone, which are widely used for cleaning utensils and in many cases for removing resin from the hands.

Our early experience was in the manufacture of large pieces of apparatus, such as radar dishes approximately $17 \mathrm{ft}$. $(5.1 \mathrm{~m}$.) long, $8 \mathrm{ft}$. $(2.43 \mathrm{~m}$.) wide, and weighing about $550 \mathrm{lb}$. (249 kg.). Polyester resin and hardener were mixed in small bowls and then applied to a framework of glass cloth by hand. The men were provided with a suitable barrier cream. Although many of these dishes were made over a period of some years and the men were regularly examined, no skin involvement was seen.

When a polyester lacquer was introduced into the wood-working section of the organization, as a coating for television and radio cabinets, and complaints of skin irritation and other reactions were reported, an investigation of the possible cause was undertaken. A recent questionnaire sent out by one of us (Bourne, 1963) on the effects of resins showed that in $\mathbf{1 5}$ factories there were at least 37 cases due to the use of polyesters.

This use of polyester has spread widely in the furniture trades, the only addition to standard formulation being the incorporation of a wax.

In early experiments to find a satisfactory combination that would set in a relatively short time, polyester resin and catalyst with accelerators were mixed in relatively small quantities in plastic vessels and then poured into a standard spray gun and applied to the cabinets in a well-exhausted spray booth, the workers being provided with face-masks, gloves, and an adequate barrier cream. As the "pot life" of the mixture at temperatures of $60^{\circ}$ to $65^{\circ} \mathrm{F}$. $\left(15.6^{\circ}\right.$ to $18.3^{\circ} \mathrm{C}$.) was only about 20 minutes, small quantities had to be made up and the spray gun refilled many times. Clogging occurred, and it was necessary to clean the receptacle of the gun and its nozzle with a solvent, usually acetone. We did not anticipate any difficulty from the use of acetone since a previously used barrier cream would give adequate protection against this, and our experience in casting radar dishes led us to believe that this barrier cream would be satisfactory.

Television cabinets, designed to take up to 21-in. cathode ray tubes, and radio cabinets are unwieldy objects to spray, and the cabinets were placed on turn-tables in the spray booths and revolved by the worker as necessary (Fig. 1). Some waste is unavoidable and the finely divided spray is partly drawn away through the exhaust system at the back of the booth and partly deposited on the walls. There 


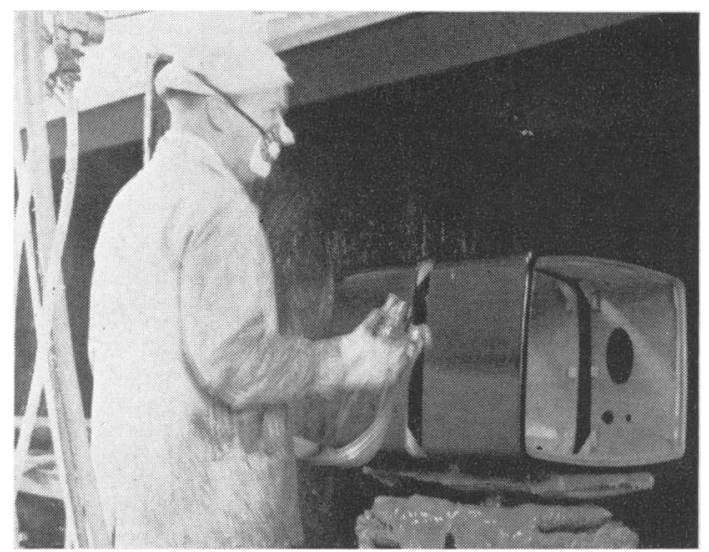

FIG. 1.-Sprayer.

is also a rebound spray from the cabinet, which soils the clothing of the operator and makes the face vulnerable, but by correct positioning an experienced operator can avoid much of the rebound. Most of the operators in the early days were transferred from cellulose spraying and were therefore able to apply a similar technique, but difficulty was experienced with new starters. The most modern spray booths are provided with a cascade system at the rear to remove excess of sprayed materials.

After some months of trial a satisfactory resin system was formulated, and it became possible to arrange for a direct feed to the spray gun and to avoid the risks of contact from mixing. A supply was so arranged that the resin and accelerator/ catalyst were fed separately into the spray gun by vacuum tubes, the one for the resin having a bore 10 times the size of that for the catalyst. The use of acetone was also much reduced by this method. The cabinets are allowed to dry at $65^{\circ} \mathrm{F} .\left(18^{\circ} \mathrm{C}\right.$.) in a dust-free atmosphere; this takes some hours and they are then sanded on the standard type of continuous belt emery sander (Fig. 2). A fine dust of resin is given off, which must be drawn away from the vicinity of the machine with efficient exhaust ventilation apparatus. The cabinets are then removed to another department where they are polished on large, soft textile buffing wheels treated with a silicone soap, and finally dry-polished on a clean buffing wheel. In the sanding rooms a fine dust of hardened polyester resin is given off, and it is almost impossible to obtain a completely dust-free atmosphere.

In 1959 one of us (L.B.B.) examined a man who was alleged to have contracted dermatitis due to polyester dust while engaged in hand-sanding tele- vision cabinets at another factory, and in 1960 a similar case was seen of alleged dermatitis from polyester dust produced while inspecting cabinets during the manufacture of television sets.

An investigation of these resins was reported from the Netherlands (Malten, 1956); of 30 workers, eight appear to have become sensitized to one or more of the substances used in the process. Malten suggested that "fumeric acid and esters of maleic acid may be the sensitizing elements in polyester resins". Stephenson and Fosdick (1960) have recently discussed the toxicity of iso-polyester resins, particularly in relation to the styrene risk.

As we had not experienced any difficulty with the manufacture of the radar dishes in which large quantities of polyester and catalyst were used, we were suspicious of the hardened resin dust as a possible cause because of our previous favourable experience with unpolymerized resins.

It is usual for resin manufacturers to state that, after hardening, the resin is fully reacted. This has not been found to be true of other synthetic resins, particularly the epoxy series (Bourne, Milner, and Alberman, 1959).

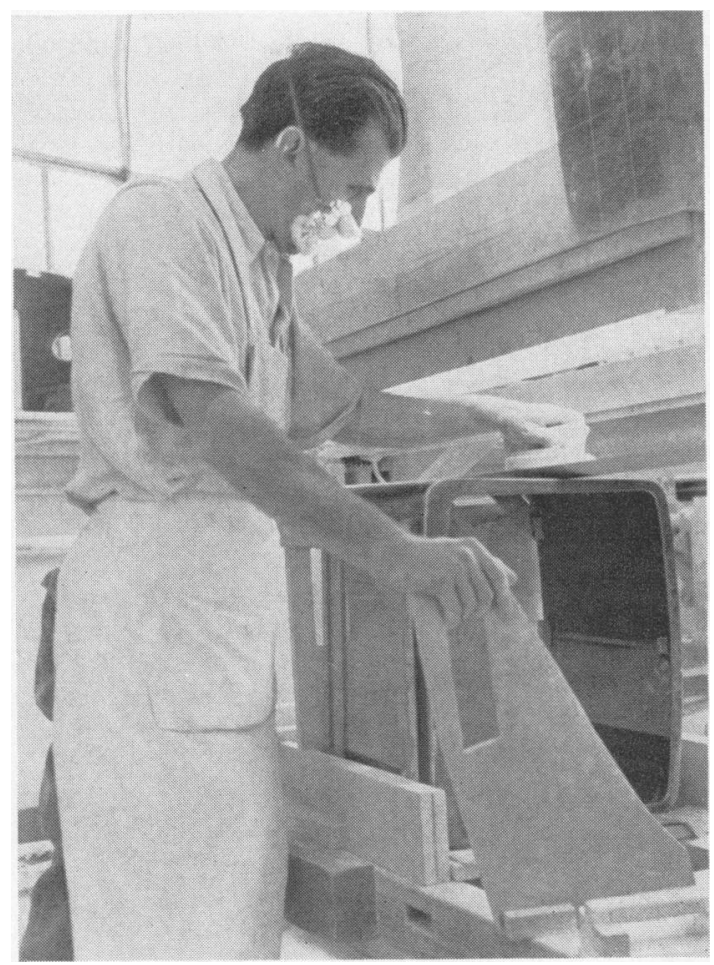

Fig. 2.-Belt sander. 
An analysis of the polyester dust from the sanding shop in our group gave the following results (Table 6).

TABLE 6

ANALYSIS OF POLYESTER DUST

\begin{tabular}{l|c}
\hline & Percentage \\
\hline Resinous matter & $93 \cdot 3$ \\
Amorphous silicone material & 2.15 \\
Oxygen & 0.08 \\
Wax & $0 \cdot 04$ \\
Cobalt metal (in the form of cobalt soap) & $0 \cdot 05$ \\
Dibutyl phthalate & 3.5 \\
Impurities & 0.88 \\
\hline
\end{tabular}

This seems to confirm the previously expressed opinion that some synthetic resins do not appear to polymerize completely.

\section{Toxicity of Components of Polyester Resin Systems}

The degree of activity of the hardened resin is difficult to establish, particularly as a potential skin irritant. Some of the constituents of the polyester mixture are known to be hazards and merit consideration.

Styrene $\left(\mathrm{C}_{6} \mathrm{H}_{5}-\mathrm{CH}-\mathrm{CH}_{2}\right.$ also known as monomeric styrene, phenyl ethylene, or vinyl benzene) is a colourless or yellowish oily liquid with a pungent aromatic odour; it polymerizes to form a glass-like solid which also has the characteristic odour. It has been used for many years in the manufacture of synthetic rubbers and as a modifier of alkyd resins. Dermatitis due to styrene has been reported (Schwartz et al. 1957). In high concentrations in air $(2,000$ to 10,000 p.p.m.) it is fatal to animals even for short exposures, the impact being mainly upon the central nervous system. In lower concentrations death may result from chemical pneumonia. The maximum allowable concentration is 100 p.p.m. Styrene resembles benzol and toluol in its defatting action on the skin. Higher or lower similar chemical compounds such as vinyl toluene are also used in place of styrene. As much as 30 to $40 \%$ of styrene is commonly present in the total resin mixture.

Stephenson and Fosdick (1960) found that "the highest concentrations of styrene vapour were recorded during the initial mixing of the resin and catalyst and during application of the mix".

R. Frant (personal communication, 1961) states: "Styrene is a rather volatile liquid, and leads to most complaints. The fact that the hardening of the polyester is an exothermic reaction increases the evaporation of the styrene: about $0.5 \mathrm{~g}$. of styrene is produced per $\mathrm{dm}^{2}$.

Styrene produces the following complaints: (1) considerable de-fatting of the skin, especially as splashes of resin can only be removed by acetone or a special cleansing cream; (2) irritation of the mucous membrane of the eyes, nose, throat, and trachea ; and (3) narcosis ("styrene sickness"), characterized by sleepiness, headache, strong sweating, and a feeling of malaise. These symptoms are to be expected at a concentration of 200 to 600 p.p.m., but some irritation is still found at the m.a.c. of 100 p.p.m."

The organic peroxide catalysts may be dangerous to handle. Those commonly used are methyl-ethylketone (M.E.K.) peroxide and benzoyl peroxide, but others available are cumene hydroperoxide, dicumyl peroxides, lauroyl peroxide, acetyl peroxide, and cyclohexanone peroxide. These are usually supplied in suspension or in solution in a plasticizer. Care must be taken to avoid all contact with the skin and eyes. Although the actual amount of peroxide in the mixture may be small ( 1 to $2 \%$ ), scrupulous care and supervision are necessary in handling and making up the final mixture. The careful disposal of contaminated peroxide rags, wipers, and gloves is of great importance, since if they are left in bins spontaneous combustion as well as the risk of further contact is possible. The Annual Report of H.M. Chief Inspector of Factories for 1958 emphasizes particularly the dangers of handling organic peroxides and lists the necessary precautions that should be instituted.

An accelerator, usually a metal salt, is used to speed up the reaction. Cobalt naphthenate is commonly used, in the proportion of 1 to $4 \%$ of a $0.01 \%$ solution in white spirit or in a plasticizer. Cobalt contact rashes were noted by Oppenheim in 1925 (quoted by Prosser White, 1934); Pirilä (1953) considers cobalt a sensitizing agent and Schwartz, Tulipan, and Birmingham (1957) list cobalt, cobalt chloride, and cobalt oxide as sensitizers but not the other salts, and designate styrene monomers as skin irritants. The only peroxide quoted by them as being an irritant is hydrogen peroxide.

Dimethylaniline, $\mathrm{C}_{6} \mathrm{H}_{5} \mathrm{~N}\left(\mathrm{CH}_{3}\right)_{2}$, which has been used in place of cobalt naphthenate, exposes the worker to a greatly increased risk. It is a yellow or brown liquid which is readily absorbed through the skin. It is listed by Schwartz et al. (1957) as a cause of dermatitis in addition to its other properties as a systemic poison, which result in methaemoglobinaemia cyanosis, anoxaemia, and depression of the central nervous system. Special precautions must be observed in its use, and all contamination, not only of the skin but of the clothing also, must be promptly dealt with. The maximum allowable concentration on the skin is as low as $\mathbf{5}$ parts per million (Ministry of Labour, 1961).

The inorganic fillers which are commonly used are not likely to cause trouble to the skin if handled 
TABLE 7

COMPONENT SENSITIVITY (MALTEN, 1956)

\begin{tabular}{|c|c|c|c|}
\hline & No. of Positives & Strength of Test Solution ( $\%$ ) & $p \mathrm{H}$ of Test Solution \\
\hline $\begin{array}{l}\text { Benzoyl peroxide } 50 \% \text { in phthalate } \\
\text { Cyclohexamine peroxide } \\
\text { Cobalt naphthenate } \\
\text { Methyl-ethyl-ketone peroxide } \\
\text { Styrene } \\
\text { Polyester hardener }+30 \% \text { styrene monomer }+ \text { inhibitor }\end{array}$ & $\begin{array}{l}3 \\
2 \\
2 \\
1 \\
1 \\
4\end{array}$ & $\begin{array}{l}5 \text { in acetone } \\
\frac{1}{2} \text { in alcohol } \\
5 \text { in alcohol } \\
\frac{1}{2} \text { in acetone } \\
5 \text { in alcohol } \\
70 \text { in acetone }\end{array}$ & $\begin{array}{l}5 \\
5 \\
5 \\
5 \\
5 \cdot 5 \\
5\end{array}$ \\
\hline
\end{tabular}

with care. Fillers of dust size finer than 200 mesh are to be avoided because of the danger of respiratory pathology. There is little doubt that impregnated glass fibre and other textile cloths when hardened make the entry of toxic agents into the epithelium easier by reason of their abrasive effect on the horny layer.

Dibutyl phthalate has not yet been reported as a skin irritant.

Malten (1956) reported in a group of 30 workers handling polyester chemicals hypersensitivity reactions shown by the results of closed patch tests (Table 7).

Of the 30 workers involved, eight became sensitized to one or other of the substances used in the process.

\section{Wood Lacquering Hazards}

R. L. Zielhuis (personal communication, 1961) found that there was no evidence of systemic toxicity in workers mainly exposed to styrene and triethylenetetramine.

Pirilä $(1953,1954)$ has referred to the difficulty with cobalt as a patch testing agent. He followed the previous published reports and used solutions of 2 to $10 \%$ concentration of cobalt chloride, nitrate, and sulphate as recommended. Pirilä found that in $\mathbf{4 3 6}$ pottery workers handling clay containing cobalt oxide 0.01 to $0.11 \%$ there were 12 positives to a $5 \%$ cobalt nitrate patch test, and of 19 workers in the clay shops with dermatitis of more than one month's duration, eight were strongly positive to the $5 \%$ solution. V. Pirilä (personal communication, 1961) also states that he has seen cobalt sensitivity in painters when the paints contained cobalt siccatives. Schwartz et al. (1957) suggest a $2 \%$ solution of cobalt chloride for patch testing.

Sax (1957) lists the hazard ratings of the components of the polyester system (Table 8).

He rates the skin absorption risk of dimethylaniline as "high".

In the cabinet works polyester department a total of 25 men were at risk from late 1957 to mid1960. Eleven were employed as sprayers, five as sanders, six as buffers, and three as labourers.

The symptoms complained of were: burns, five (all sprayers); and erythemata, eight (two sprayers,
TABLE 8

HAZARD RATINGS OF COMPONENTS OF POLYESTER SYSTEM

\begin{tabular}{|c|c|c|c|}
\hline & $\begin{array}{l}\text { Acute Local } \\
\text { Effects }\end{array}$ & $\begin{array}{c}\text { Chronic Local } \\
\text { Effects }\end{array}$ & Allergenic \\
\hline $\begin{array}{l}\text { Cobalt compounds } \\
\text { (acetate and nitrate) } \\
\text { Styrene monomer } \\
\text { Methyl-ethyl-ketone } \\
\text { Cumene dioxide } \\
\text { Benzoyl peroxide } \\
\text { Dibutyl phthalate } \\
\text { Dimethylaniline }\end{array}$ & $\begin{array}{l}\text { Slight } \\
\text { Moderate } \\
\text { Slight } \\
\text { High } \\
\text { Moderate } \\
\text { Slight } \\
\text { None }\end{array}$ & $\begin{array}{l}\text { Slight } \\
\text { Moderate } \\
\text { Slight } \\
\text { Unknown } \\
\text { Moderate } \\
\text { Unknown } \\
\text { Unknnwn }\end{array}$ & $\begin{array}{r}\text { Slight } \\
\text { Slight } \\
- \\
-\end{array}$ \\
\hline
\end{tabular}

one sander, two buffers, and three labourers). Of those with erythemata, four subsequently developed papules and vesicles, one an acute facial allergic reaction, and another generalized allergic erythema.

All the burns occurred in sprayers who handled the resin or hardener in a liquid state. The burns, which develop signs in from 20 minutes to 24 hours after contact, give rise to tense throbbing vesicles (Fig. 3). Treatment by immediate washing with warm soapy water followed by calamine lotion prevented some burns developing and reduced the incidence of erythema subsequently. The introduction of resin-removing cream materially assisted in preventing further burns.

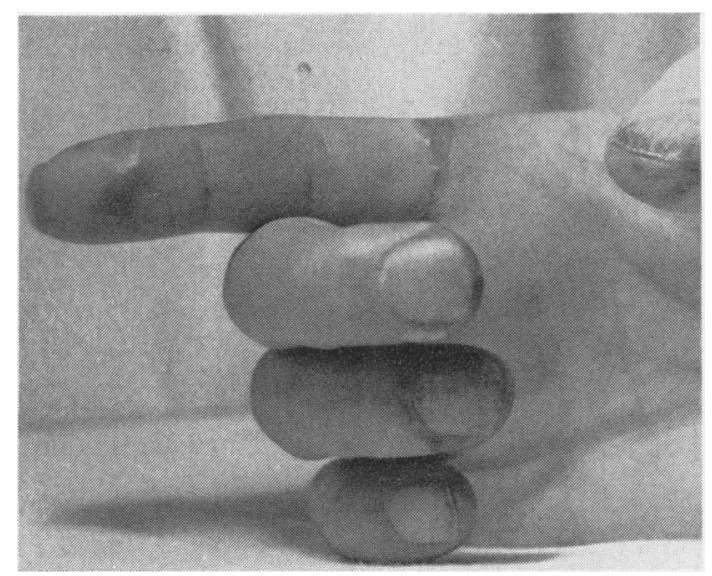

Fig. 3.-Burn. A tense vesicle has developed on the terminal phalanx and another has broken over the metacarpo-phalangeal 


\section{Case Histories}

Some detailed case histories follow.

Case 1.-A sprayer, aged 54, began work on March 13, 1957 as a trainee sprayer. He was transferred to the polyester department in July 1958 . On September 8, he had dermatitis of both hands. He returned to work on September 15. The next day he complained of irritation of both hands on first exposure. They were cleaned with acetone and then became much worse with acute erythema and oedema, followed by fissuring and desquamation.

He returned to work on December 22. In 12 hours his hands had again become erythematous and itching, although he was wearing heavy cotton gloves. The skin was much worse with scaling and fissuring. The neck was erythematous.

When seen on February 11 he said he had been an inpatient in a general hospital, where he was patch-tested with resin and catalyst in petroleum jelly. The dermatologist reported, "I think that although the patch tests were negative there can be no doubt that he has a contact irritation to one or more of the substances he is in contact with at work." The hospital was informed that we were not surprised at the results, as the irritants were no doubt well diluted and in addition reactions may well have taken place between the jelly and the resin and catalysts. We sent the patient back with samples of each constituent of the resin and catalyst, but no further tests were attempted. He was then patch-tested at the factory with an immediate positive reaction to the catalyst, which remained so for some five weeks afterwards. He was transferred to other work.

Case 15.-A buffing trainee, aged 19, started work on September 14, 1959. One hour later, after watching others at work, he was unable to breathe, and the left eye and left nostril swelled. He went home and saw his doctor who sent him to an E.N.T. hospital for antral puncture and washout. He did not resume work.

Case 16.-A sprayer, aged 20, was taken on as a trainee on June 3, 1959. On August 26 he had an itching red rash of the forearms, and a red rash of the chest and back with slight itching for the past two days. When seen on September 3 he had papules on both hands, and the next day both hands were badly swollen with intense itching. He was in hospital for two weeks. On September 21 he returned to work, although he still had desquamation of both hands.

Case 17.-A labourer, aged 67, began work on August 17, 1959, removing cabinets in a "tacky" state after spraying. After three weeks he complained of itching of the hands. When seen on September 18 he had a rash on the backs of both hands. On September 21 there were a few papules and erythema on the backs of both hands, which he said were possibly due to rubber gloves and sweat. He was then wearing cotton gloves and the itching of the hands was relieved. He said that if he touched his face with resin there was a burning effect for 10 minutes.
Case 18.-A West Indian sander and sprayer was seen on October 8,1959, complaining of erythema of both wrists, which was worse at night. He began work on August 10, and had no trouble. He was transferred to spraying on August 31 and that day splashed catalyst while pumping on to his arms; one hour later he felt a burning sensation. He had a burn on the arm and on the palms. On September 21 there were marked burns of the upper arms with scarring. He has returned to the same work without trouble.

Case 19.-A Bengali sander and sprayer, aged 25, started work on August 31, 1959, and was for two days on sanding; he was then transferred to spraying. When pumping catalyst he splashed some on to the left upper forearm. He allowed it to dry and blisters formed in 12 hours. When seen on September 21 there was a scar of a healing burn in the left cubital fossa. He said he felt no effect from the resin or resin plus catalyst.

On October 8 he upset a container of resin which he was carrying on his shoulder, soiled his shirt and the skin of his back and shoulder. In 10 minutes he complained of a burning sensation. He washed the area with soap and water and has had no trouble since.

Case 27.-A labourer, aged 27, began work on October 6, 1954, and worked in charge of a cyclone dust extraction plant for all kinds of wood dust without any difficulty in spite of a history of bronchitis. On October 8 he complained of itching all over the body with red blotches on the arms when at work, which recovered at week-ends. When he wore a Martindale mask, blisters and sores around the mouth developed and he had to leave off the mask. He had dry cracked lips and healing vesicles around the mouth. A more efficient respirator was provided but he left work on October 23, 1959.

It was decided to patch-test volunteers who had skin lesions and who had recovered or were in a quiescent state, using constituents of the resin system which were probable irritants. Solutions of the following were used: monomeric styrene $1 \%$ in butyl phthalate, cobalt nitrate $5 \%$ and $10 \%$, cobalt acetate $1 \%$ (diluted 1 in 10 and 1 in 20), and M.E.K. peroxide in butanol.

All five men were tested with the cobalt solutions by standard closed patch tests and controls, and only one (Case 16) gave a doubtful positive erythema in 48 hours to the stronger cobalt acetate solution. Open skin tests of styrene and peroxide gave four negative results, one immediate positive (Case 27) to styrene, and one strong positive to the catalyst (Case 1). It is probable that the testing solutions were not strong enough but, in view of the burns from which some of the men suffered, we felt it was wiser to keep to low levels of possible irritancy.

The suppliers of the resins, catalysts, and hardeners have appreciated the risks in using these materials. A leading firm of suppliers in its Polyester 
Handbook (Scott Bader and Co., Ltd., 1959) advises:

\begin{abstract}
"Some types of $\mathrm{C}$ and $\mathrm{M}$ resin contain monomeric styrene which is a good grease solvent. Care should be taken to wash all resin from the hands with acetone followed by a wash in soap and water. In warm weather, when the pores of the skin are more open, it is recommended to use a barrier cream. If these simple precautions are taken there should be no fear of dermatitis. For cleaning the hands a resin-removing cream will be found satisfactory."
\end{abstract}

We do not approve of the use of acetone in these instructions as it is a fat solvent. The resin-removing cream should be adequate.

Peroxide manufacturers are well aware of the explosion and fire risks and also of the effect on the skin. One manufacturer gives this warning:

"Organic peroxides are toxic and are also strong oxidizing agents which will damage human tissue. Therefore, in case of contact with skin, a good wash with warm water and soap is required. For eyes immediate medical attention is essential. If this cannot be given instantly, a prolonged irrigation with water, preferably distilled water or eye lotion such as 'optrex', containing about $5 \%$ of sodium ascorbate must be applied. If a peroxide is accidently swallowed a solution of sodium ascorbate must be applied immediately as a stomach washout."

Our problem arose from the handling and use of relatively small amounts of these materials, but in large production a "no-touch" technique is possible with modern machinery.

The Ford Motor Company of the U.S.A. have installed a totally enclosed plant handling up to $2,400 \mathrm{lb}$. $(1,088 \mathrm{~kg}$.) per hour of a reinforced polyester mix which includes resin catalyst, sisal fibres, calcium carbonate, and clay and asbestos fillers (Chemical Processing, 1960).

In the smaller factories there is usually inadequate supervision, and the precautions which should be brought to the notice of all staff are embodied in our following suggested Code of Practice:

\section{Precautions for Handling Polyester Resins}

1. Instruction and education of all staff in the hazards involved should be provided.

2. Only limited quantities of materials must be made available from stores. In practice this should be restricted to the amount necessary for the shift or at most for the day's work.

3. A routine technique should be adopted so that a complete cycle of operation is used, i.e. weighing, mixing, pouring, loading spray gun, and so on.

4. Mixing must take place in a well-ventilated booth.

5. Mixing benches should have a readily removable paper cover which can be changed when soiled.
6. A suitable barrier cream should be provided at the work bench and used regularly, and instruction in its use should be constantly reviewed.

7. Resin-removing creams must be available at the work bench with a supply of clean rag or paper towels.

8. Protective clothing and, if necessary, face-masks must be used.

9. Good washing facilities with automatic draw-down towels should be provided.

10. There must be thorough cleansing of the hands before using toilets.

11. There must be strict control over the issue of solvents, particularly acetone and similar compounds, and these must never be used for removal of resins from the skin.

12. Hardened and waste resin should be thrown away or destroyed by incineration outside the works.

13. Containers used for mixing resins should be placed after use in lidded bins and disposed of daily by incineration.

14. Small tools such as brushes should be provided with hand guards to prevent resin flowing up on the handle.

15. Recommended containers for components, particularly peroxides, must be used and all fire risks avoided.

16. Where hardened resin is worked (sawn, filed, etc.) all dust should be efficiently exhausted.

17. Regular inspection of the staff and department by supervisory staff is necessary.

It is obvious that a good handling technique must be introduced so that no materials touch the skin. Atmospheric pollution from volatile materials or hardened resin dust must be reduced to safe levels. Totally enclosed automatic mixing of glass fibre, filler, resin, and catalysts may be undertaken in modern spraying machines.

Our workers have never used dimethylaniline, but where it is used scrupulous cleanliness must be enforced. In view of its high skin absorption rate, all splashes on the skin and clothing must be removed as soon as possible. Two cases of poisoning from aniline-containing catalysts have been reported to us (Bourne, 1963).

Spraying of these resins inside tanks, storage chambers, and ship holds is commonly undertaken. As there is an increased danger of air pollution under these conditions, it may be necessary to enclose the workers in protective clothing and supply an air line to the inside of helmets or masks (Fig. 4).

In other spraying operations, the exhaust ventilation must be efficient in all booths. The resin mixtures become deposited on the vents and harden at the back and sides of the booths, obstructing the free passage of air. This can be greatly reduced by a cascade water system at the rear of the booths. The only difficulty with this method is the clogging up of the filters which must be cleaned out regularly. 


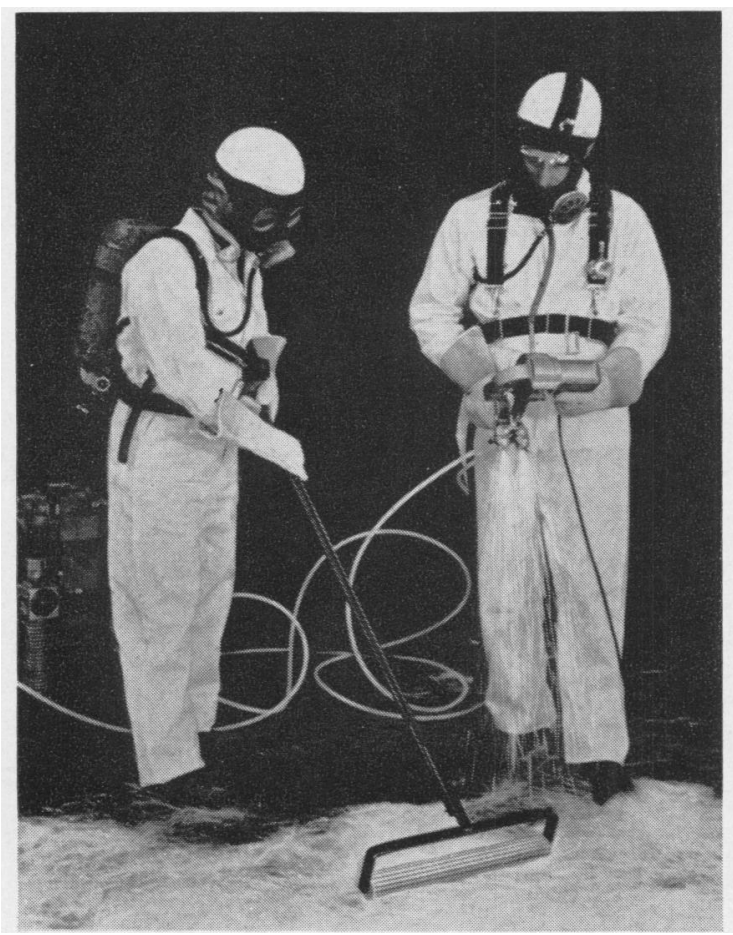

FIG. 4.-Glass fibre and resin are applied in an enclosed space. The operators are fully protected and each is supplied with an air line (Extrudex, Ltd.).
Since installing the cascade system, our workers have only found it necessary to wear gloves and light face-masks. Care must be taken in pouring, mixing, and filling spray guns and in cleaning brushes when these are used. It is usual to clean them with solvents which may themselves constitute skin and fire hazards.

Our thanks are due to Mr. B. Parkyn of Scott Bader and Company, Ltd., Mr. P. G. Pentz of Leicester Lovell and Company, Ltd., Dr. V. Pirilä, Dr. R. Frant, Dr. R. L. Zielhuis, and other colleagues for valuable information.

\section{REFERENCES}

Bourne, L. B. (1963). Practitioner. In the press.

Milner, F. J. M., and Alberman, K. B. (1959). Brit. J. industr. Med., 16, 81.

British Patent. 393034.

Chemical Processing (1960). March, 20.

H.M. Chief Inspector of Factories (1959). Annual Report for 1958 , p. 25. H.M.S.O., London.

Kienle, R. H., and Hovey, A. G. (1930). J. Amer. chem. Soc., 52, 3636 Quoted by Parkyn and Hulbert, 1959.

Malten, K. E. (1956). Verh. Ned. Inst. Prev. Geneesk. Leiden, 32.

Ministry of Labour (1961). Toxic Substances in Factory Atmospheres. H.M.S.O., London.

Parkyn, B., and Hulbert, G. C. (1959). Appl. Plastics, 2, no. 4, p. 32 and no. 5, p. 33 .

Pirilä. V. (1953). Acta derm. venereol. (Stockh.), 33, 193.

- (1954). ibid., 34, 136.

Resin News (1961). October, $1,10$.

Sax, N. I. (1957). Dangerous Properties of Industrial Materials, 2nd ed. Reinhold, New York.

Schwartz, L., Tulipan, L., and Birmingham, D. J. (1957). Occupational Diseases of the Skin, 3rd ed. Kimpton, London.

Scott Bader \& Co., Ltd. (1959). Polyester Handbook, p. 15.

Stephenson, R. W., and Fosdick, L. B. (1960). Industr. Hyg. J., 21, 522.

Vorländer, D. (1894). Liebig's Ann. Chem., 280, 167. Quoted by Parkyn and Hulbert, 1959.

White, R. Prosser (1934). The Dermatergoses or Occupational Affections of the Skin, 4th ed. Lewis, London. 